\title{
High-Resolution Detection of Quantitative Trait Loci for Seven Important Yield Components in Wheat (Triticum aestivum L.) using a High-Density SALF-Seq Genetic Map
}

Tao Li

Triticeae Research Institute, Sichuan Agricultural University

Qiao Li

Chengdu Institute of Biology, Chinese Academy of Sciences

Jinhui Wang

Chengdu Institute of Biology, Chinese Academy of Sciences

\section{Zhao Yang}

Chengdu Institute of Biology, Chinese Academy of Sciences

Yanyan Tang

Chengdu Institute of Biology, Chinese Academy of Sciences

Yan Su

Chengdu Institute of Biology, Chinese Academy of Sciences Juanyu Zhang

Chengdu Institute of Biology, Chinese Academy of Sciences Xvebing Qiu

Chengdu Institute of Biology, Chinese Academy of Sciences

Xi Pu

Chengdu Institute of Biology, Chinese Academy of Sciences

Zhifen Pan

Chengdu Institute of Biology, Chinese Academy of Sciences

Haili Zhang

Chengdu Institute of Biology, Chinese Academy of Sciences

Junjun Liang

Chengdu Institute of Biology, Chinese Academy of Sciences

Zehou Liu

Crop Research Institute, Sichuan Academy of Agricultural Sciences

Jun Li

Crop Research Institute, Sichuan Academy of Agricultural Sciences

Wuyun Yang

Crop Research Institute, Sichuan Academy of Agricultural Sciences

Maoqun Yu

Chengdu Institute of Biology, Chinese Academy of Sciences

Hai Long

Chengdu Institute of Biology, Chinese Academy of Sciences

Yuming Wei

Triticeae Research Institute, Sichuan Agricultural University

Guangbing Deng ( $\nabla$ denggb@cib.ac.cn)

Chengdu Institute of Biology, Chinese Academy of Sciences

\section{Research Article}

Keywords: wheat, yield, yield components, specific-locus amplifed fragment (SALF), linkage analysis.

Posted Date: August 26th, 2021

DOI: https://doi.org/10.21203/rs.3.rs-783221/v1

License: (c) (i) This work is licensed under a Creative Commons Attribution 4.0 International License. Read Full License 


\section{Abstract}

Background: Yield-related traits including thousand grain weight (TGW), grain number per spike (GNS), grain width (GW), grain length (GL), plant height (PH), spike length (SL), and spikelet number per spike (SNS) are greatly associated with wheat (Triticum aestivum L.) grain yield. To detect quantitative trait loci (QTL) associated with them, 193 recombinant inbred lines derived from two elite winter wheat varieties Chuanmai42 and Chuanmai39 were employed to perform QTL mapping in six or eight environments.

Results: A total of 30 QTLs on chromosomes 1A, 1B, 1D, 2A, 2B, 2D, 3A, 4A, 5A, 5B, 6A, 6D, 7A, 7B and 7D were identified. Among them, six major QTLs QTgw.cib-6A.1, QTgw.cib-6A.2, QGw.cib-6A, QGI.cib-3A, QGI.cib-6A, and QSI.cib-2D explaining 5.96-23.75\% of the phenotypic variance were detected in multiple environments and showed strong and stable effects on corresponding traits. Three QTL clusters on chromosomes 2D and 6A containing 10 QTLs were also detected, which showed significant pleiotropic effects on multiple traits. Additionally, three Kompetitive Allele Specific PCR (KASP) markers linked to five of these major QTLs were developed. Candidate genes of QTgw.cib-6A.1/QGI.cib-6A and QGI.cib-3A were analyzed based on the spatiotemporal expression patterns, gene annotation, and orthologous search.

Conclusions: Six major QTLs for TGW, GL, GW and SL were detected. Three KASP markers linked with five of these major QTLs were developed. These QTLs and KASP markers will be useful for elucidating the genetic architecture of grian yield and developing new wheat varieties with high and stable yield in wheat.

\section{Background}

Common wheat (Triticum aestivum L.) is one of the three major crops worldwide and provides approximately $30 \%$ of global grain production and $20 \%$ of the calories consumed for humans [1]. Due to ongoing decrease of the global arable cultivated land area and increase of the population, the current rate of wheat yield increase will be insufficient to meet the future demand. The development of high-yield varieties, one of the important targets of modern wheat breeding programs worldwide, thus must be accelerated to fulfill future global food and nutrition security [2]

Wheat yield is a complex quantitative trait controlled by multiple genes and significantly influenced by interacting genetic and environmental factors [3, 4]. By contrast, yield components including thousand grain weight (TGW), grain number per spike (GNS), grain width (GW), grain length (GL), plant height (PH), spike length (SL) and spikelet number per spike (SNS) typically show higher heritability than that of the yield [5-7]. Therefore, targeting these traits and identifying the related genes or quantitative trait loci (QTL) is an important approach to improve grain yield potential in wheat.

To date, several genes associated with wheat yield have been mapped and cloned in wheat. For example, the application of semi-dwarfng genes $R h t-B 1 b$ and $R h t-D 1 b$ not only effectively improved the lodging resistance but also improved the harvest index, resulting in increased yields since the 1970s [8-10]. The vernalization insensitive alleles of $V r n-1$ ( Vrn-A1, Vrn-B1, and $V r n-D 1)$ shorten both the vegetative and the reproductive stages and have considerable impact on spike morphological traits $[11,12]$. TaGW2 homologous to rice GW2 was located on chromosome 6 A and could alter grain width and weight and to lesser extend grain length owing to changes in the width of the spikelet hull $[13,14]$. The grain-shape gene TasgD1 encoding a Ser/Thr protein kinase glycogen synthase kinase3 and independently control semispherical grain trait [15]. A jasmonic acid synthetic gene keto-acyl thiolase 2B was cloned in a TGW mutant and showed significant effect on TGW and GW [16].

Before the gene cloning, quantitative trait loci (QTL) mapping provides an effective approach to depict the genetic architecture of complex quantitative traits. Over the past decades, numerous QTLs associated with yield or yield components have been identified on all wheat chromosomes [3, 4, 11, 17-23]. For example, Rht8 located on chromosome 2DS was closely linked with marker $x f d c 53$ and reduced plant height by $10 \%$ [24]; Rht25 on wheat chromosome arm 6AS showed pleiotropic effects on coleoptile length, heading date, SL, SNS and grain weight [25]. Two major QTLs for grain size and weight were detected on chromosome $4 \mathrm{~B}$, which together explained $46.3 \%$ of the phenotypic variance [26, 27]. Five stable QTLs for PH, SL and HD on chromosomes $1 \mathrm{~A}, 2 \mathrm{~A}, 2 \mathrm{D}$ and $6 \mathrm{~A}$ were detected in an introgression line population [28]. Twelve major genomic regions with stable QTL controlling yield-related traits were detected on chromosomes 1B, 2A, 2B, 2D, 3A, 4A, 4B, 4D, 5A, 6A, and 7A [1]. However, among those QTLs reported previously, few of them were stably detected in multienvironments, which greatly restricts their potential utilization in marker-assisted selection (MAS) in breeding programs. Additionally, the lower density of genetic maps also limits the resolution and accurancy of the QTL intervals reported previously.

In the present study, a high-resolution genetic map constructed through specific-locus amplifed fragment (SALF) sequencing was adopted for detection of yield componant QTLs in a recombinant inbred line (RIL) population derived from two elite winter wheat varieties Chuanmai42 (CM42) and Chuanmai39 (CM39) [29]. Seven traits including TGW, GW, GL, PH, GNS, SL and SNS were assessed in multiple environments to detected potential major and stable QTL, which will lay out a foundation for further study on fine mapping and cloning of the underlying key genes for yield.

\section{Results}

\section{Phenotypic variation}

The measured traits of the CM42×CM39 RILs as well as the two parents are listed in Table 1. CM42 had higher trait values for TGW, GW, GL, GNS, PH and SL than those of CM39 in each of environments and the best linear unbiased prediction (BLUP) datasets. In the RIL population, all traits showed wide and significant variations in all environments and the BLUP datasets (Table 1). Of them, the TGW ranges from 20.81 to $72.7 \mathrm{gram}$ (g), the GW ranged from 2.6 to 4.21 millimeter $(\mathrm{mm})$, the GL ranged from 5.88 to $8.81 \mathrm{~mm}$, the PH ranged from 65.08 to 148.3 centimeter (cm), the GNS ranged from 24 to 81.2 , the SL ranged from 6.65 to $18.17 \mathrm{~cm}$, and the SNS ranged from 15.83 to 27 (Table 1), respectively. The BLUP datasets of all traits showed normal distributions in the RIL lines, which suggests polygenic inheritance of these traits (Fig. 1A). Additionally, the TGW, GL, PH, GNS and SL showed high broad-sense heritability of 
$0.54,0.6,0.91,0.66$ and 0.88 , respectively (Table 1$)$. Significant and positive correlations $(P<0.01)$ of the measured traits among all environments and the BLUP datasets were detected, which suggested that these traits were environmentally stable and mainly controlled by genetic factors (Table S2). 
Table 1

Phenotypic variation of seven yield components, including thousand grain weight (TGW), grain number per spike (GNS), grain width $(\mathrm{GW})$, grain length $(\mathrm{GL})$, plant height $(\mathrm{PH})$, spike length $(\mathrm{SL})$ and spikelet number per spike (SNS), for the parents and the

\begin{tabular}{|c|c|c|c|c|c|c|c|c|}
\hline \multirow[t]{2}{*}{ Traits } & \multirow[t]{2}{*}{ Environments } & \multicolumn{2}{|c|}{ Prarents } & \multicolumn{5}{|c|}{ The CM42×CM39 RIL lines } \\
\hline & & CM42 & СМз9 & Range & Mean & SD & $\mathrm{CV}(\%)$ & $\mathrm{H}^{2}$ \\
\hline \multirow[t]{7}{*}{ TGW } & 2017SHF & 54 & 52.94 & $38.34-70.88$ & 58.57 & 5.84 & 9.98 & 0.54 \\
\hline & 2017SHL & 50.64 & 41.83 & $20.81-68.14$ & 43.76 & 9.17 & 20.95 & \\
\hline & 2018SHF & 54.79 & 53.47 & $40.44-72.7$ & 54.67 & 5.58 & 10.2 & \\
\hline & 2018SHL & 53.06 & 51.29 & $37.89-67.33$ & 54.51 & 5.57 & 10.22 & \\
\hline & 2019SHF & 52.4 & 42.42 & $32.59-66.54$ & 51.27 & 5.94 & 11.59 & \\
\hline & 2019SHL & 51.05 & 47.38 & $23.4-62.74$ & 46.9 & 6.22 & 13.27 & \\
\hline & BLUP & 52.36 & 50.44 & $38.24-62.56$ & 51.65 & 3.98 & 7.7 & \\
\hline \multirow[t]{7}{*}{ GW } & 2017SHF & 3.68 & 3.42 & $3.19-4.21$ & 3.82 & 0.16 & 4.28 & 0.49 \\
\hline & 2017SHL & 3.54 & 3.31 & $2.6-4.01$ & 3.38 & 0.29 & 8.57 & \\
\hline & 2018SHF & 3.58 & 3.53 & $3.19-4.04$ & 3.69 & 0.16 & 4.35 & \\
\hline & 2018SHL & 3.63 & 3.61 & $3.15-3.96$ & 3.65 & 0.15 & 4.14 & \\
\hline & 2019SHF & 3.6 & 3.16 & 3-3.9 & 3.5 & 0.18 & 5.21 & \\
\hline & 2019SHL & 3.56 & 3.49 & $2.84-3.99$ & 3.49 & 0.19 & 5.37 & \\
\hline & BLUP & 3.59 & 3.51 & $3.21-3.87$ & 3.59 & 0.11 & 3.06 & \\
\hline \multirow[t]{7}{*}{$\mathrm{GL}$} & 2017SHF & 7.73 & 7.17 & $6.78-8.81$ & 7.76 & 0.41 & 5.26 & 0.6 \\
\hline & 2017SHL & 6.95 & 6.53 & 5.94-7.89 & 6.86 & 0.37 & 5.39 & \\
\hline & 2018SHF & 6.87 & 6.72 & $5.89-7.92$ & 6.95 & 0.37 & 5.3 & \\
\hline & 2018SHL & 7.64 & 6.55 & $5.88-7.81$ & 6.85 & 0.37 & 5.45 & \\
\hline & 2019SHF & 7.32 & 6.43 & $6-7.71$ & 6.86 & 0.33 & 4.84 & \\
\hline & 2019SHL & 7.22 & 6.67 & 6.03-7.71 & 6.94 & 0.36 & 5.15 & \\
\hline & BLUP & 7.27 & 6.98 & 6.19-7.75 & 7.04 & 0.3 & 4.26 & \\
\hline \multirow[t]{9}{*}{$\mathrm{PH}$} & 2016SHF & 90.34 & 89.5 & $66.5-120.3$ & 91.53 & 9.5 & 10.38 & 0.91 \\
\hline & 2016SHL & 89.8 & 87.2 & $76-148.3$ & 95.97 & 10.49 & 10.93 & \\
\hline & 2017SHF & 97.67 & 96.33 & 81.33-143 & 103.3 & 10.65 & 10.31 & \\
\hline & 2017SHL & 99 & 98.8 & $66.63-121.2$ & 91.39 & 9.73 & 10.65 & \\
\hline & 2018SHF & 91.7 & 87.08 & 65.08-131.9 & 93.9 & 11.82 & 12.59 & \\
\hline & 2018SHL & 94.61 & 90 & $70.8-135.4$ & 95.57 & 11.32 & 11.84 & \\
\hline & 2019SHF & 90.05 & 85.9 & $69.45-126.8$ & 98.74 & 9.89 & 10.02 & \\
\hline & 2019SHL & 93.33 & 89.3 & $78.5-127.4$ & 97.58 & 8.98 & 9.21 & \\
\hline & BLUP & 93.24 & 91.91 & $74.65-127.5$ & 96 & 9.14 & 9.52 & \\
\hline \multirow[t]{7}{*}{ GNS } & 2017SHF & 54 & 52 & $24-81.2$ & 51.01 & 10.39 & 20.38 & 0.66 \\
\hline & 2017SHL & 44.5 & 43.6 & $26-77$ & 41.94 & 8.08 & 19.27 & \\
\hline & 2018SHF & 54.6 & 49.9 & $31.6-70.8$ & 45.62 & 6.11 & 13.4 & \\
\hline & 2018SHL & 54.5 & 54.1 & $35.3-70.8$ & 52.07 & 7.18 & 13.78 & \\
\hline & 2019SHF & 55.7 & 53.7 & $35.2-84.6$ & 53.66 & 8.18 & 15.24 & \\
\hline & 2019SHL & 56.5 & 56.2 & $35.5-75.8$ & 53.77 & 7.07 & 13.15 & \\
\hline & BLUP & 53.17 & 52.44 & $37.76-66.18$ & 49.85 & 4.62 & 9.26 & \\
\hline$S L$ & 2016SHF & 12.18 & 9.96 & $8.67-18$ & 13.09 & 1.75 & 13.37 & 0.88 \\
\hline
\end{tabular}

SHF, Shifang; SHL, Shuangliu, BLUP, best linear unbiased prediction; $C V$, coefficient of variation; $H^{2}$, broad-sense heritability 


\begin{tabular}{|c|c|c|c|c|c|c|c|c|}
\hline \multirow[t]{2}{*}{ Traits } & \multirow[t]{2}{*}{ Environments } & \multicolumn{2}{|c|}{ Prarents } & \multicolumn{5}{|c|}{ The CM42×CM39 RIL lines } \\
\hline & & CM42 & СМз9 & Range & Mean & SD & $\mathrm{CV}(\%)$ & $\mathrm{H}^{2}$ \\
\hline & $2016 \mathrm{SHL}$ & 12.1 & 9 & $6.65-14$ & 10.53 & 1.61 & 15.33 & \\
\hline & 2017SHF & 13.5 & 11.5 & $8.5-17.88$ & 13.04 & 1.73 & 13.23 & \\
\hline & 2017SHL & 13 & 11.5 & $8.33-17.67$ & 12.93 & 1.88 & 14.51 & \\
\hline & 2018SHF & 11.85 & 9.26 & $7.63-14.93$ & 11.82 & 1.84 & 15.54 & \\
\hline & 2018SHL & 13.02 & 10.9 & $7.55-15.7$ & 11.3 & 1.72 & 15.18 & \\
\hline & 2019SHF & 13.71 & 11.2 & 8.89-18.17 & 13.25 & 1.87 & 14.15 & \\
\hline & 2019SHL & 12.4 & 10.5 & $8.5-16.3$ & 12.51 & 1.56 & 12.51 & \\
\hline & BLUP & 12.71 & 11.6 & $8.45-15.69$ & 12.31 & 1.5 & 12.22 & \\
\hline \multirow[t]{7}{*}{ SNS } & 2017SHF & 18.6 & 19.6 & $16.2-25$ & 19.58 & 1.39 & 7.08 & 0.4 \\
\hline & 2017SHL & 21.2 & 21.2 & $18-27$ & 21.4 & 1.63 & 7.63 & \\
\hline & 2018SHF & 21.9 & 21.5 & $17.7-24.5$ & 21.66 & 1.13 & 5.2 & \\
\hline & 2018SHL & 20.9 & 20.7 & $17.9-25.2$ & 21.02 & 1.22 & 5.81 & \\
\hline & 2019SHF & 21.7 & 21.2 & $17.9-25$ & 21.29 & 1.2 & 5.63 & \\
\hline & 2019SHL & 17.2 & 18.1 & $15.83-21.2$ & 18.35 & 1.04 & 5.67 & \\
\hline & BLUP & 20.3 & 20.35 & $18.42-22.96$ & 20.55 & 0.84 & 4.1 & \\
\hline
\end{tabular}

\section{Correlation analyses among different traits}

The BLUP datasets of each trait was employed to assess their correlations in the CM42×CM39 RIL population. TGW had significantly positive correlation with GW, GL, PH and SL, and significantly negative correlation with GNS and SNS $(P<0.001)$ (Fig. 1). GW was significantly and positively correlated with GL ( $<<$ 0.001), weakly and positively correlated with $S L(P<0.05)$, significantly and negatively correlated with GNS and SNS ( $<<0.001)$, and not correlated with $P H$, respectively (Fig. 1). GL had significantly positive correlation with $\mathrm{PH}$ and $\mathrm{SL}(\mathrm{P}<0.001)$, significantly negative correlation with GNS $(\mathrm{P}<0.001)$, and weakly negative correlation with SNS ( $\mathrm{P}<0.05)$ (Fig. 1). Moreover, significantly positive correlations between $\mathrm{PH}$ and $\mathrm{SL}, \mathrm{GNS}$ and $\mathrm{SNS}$, and $\mathrm{SL}$ and $\mathrm{SNS}(\mathrm{P}<0.001)$, weakly positive correlations between PH and SNS $(\mathrm{P}<0.05)$, significantly negative correlations between $\mathrm{PH}$ and GNS $(\mathrm{P}<0.001)$, and no correlations between GNS and SL were detected, respectively (Fig. 1).

\section{QTL detection}

Phenotypic data of all traits evaluated in each environment and the BLUP datasets were used for QTL detection, in which the BLUP datasets were treated as an additional environment. A total of 30 QTLs were identified in multiple environments and located on all chromosomes excepting 3B, 3D, 4B, 4D, 5D and 6B (Table 2).

For TGW, two QTLs were detected on chromosomes 6A. QTgw.cib-6A.1 was detected in two environments and the BLUP datasets, explaining 9.89-16.38\% of the phenotypic variance. QTgw.cib-6A.2 was a major QTL detected in four environments and the BLUP datases and explained 15.31-23.75\% of the phenotypic variance. Alleles of CM42 for the two QTLs contributed to higher TGW (Table 2).

For GW, six QTLs were identified on chromosomes 2A, 2B, 5A, 6A and 7B. Of them, a major QTL QGW.cib-6A was identified in four environments and the BLUP datasets, explaining 8.6-23.31\% of the GW variation. The allele of CM42 contributed positively to the GW. The rest five minor QTLs were identified in two environments and explained 5.2-9.89\% of the GW variation. The favorable alleles of QGW.cib-2A and QGW.cib-5A were contributed by CM39, and that of QGw.cib-2B.1, QGW.cib-2B.2 and QGW.cib-7B were contributed by CM42 (Table 2).

Among the six QTLs for GL, two major QTL QGI.cib-3A and QGI.cib-6A were identified in five environments and the BLUP datasets, explaining 6.55-11.86\% and $5.96-13.11 \%$ of the GL variation, respectively. The positive additive effects of the two QTLs on GL were contributed by CM42. The rest four minor QTLs were identified in two or three environments on chromosoems 5A, 6D and 7D, explaining 5.17-11.34\% of the GL variation. The positive alleles of QGI.cib-5A.1, QGI.cib-5A.2 and QGI.cib-7D were derived from CM42, and that of QGI.cib-6D was from CM39 (Table 2).

Among the six QTLs for PH, QPh.cib-2D on chromosome 2D was a stable QTL and detected in five environments and the BLUP datasets, explaining 4.54$9.38 \%$ of the $\mathrm{PH}$ variation. The allele of $\mathrm{CM} 39$ contributed to higher $\mathrm{PH}$. The rest five minor QTLs on chromosomes $1 \mathrm{~A}, 4 \mathrm{~A}, 5 \mathrm{~A}, 5 \mathrm{~B}$ and $6 \mathrm{~A}$ were detected in two or three environments, explaining 3.8-11.37\% of the PH variation. The positive alleles of $Q P h . c i b-1 A$ and $Q P h . c i b-5 B$ were from CM39, and that of $Q P h . c i b-4 A$, QPh.cib-5A and QPh.cib-6A were from CM42 (Table 2).

Two minor QTLs for GNS on chromosomes 2D and 6A were detected in two environments and the BLUP datasets and explained 4.97-6.46\% and 6.56-7.73\% of the GNS variation, respectively. Alleles from CM42 and CM39 at QGns.cib-2D and QGns.cib-6A, respectively, contributed to positive effects on GNS (Table 2). 
For SL, four QTLs were detected on chromosomes 2D, 5A, 5B and 6A. A major QTL QSI.cib-2D was detected in eight environments and the BLUP datasets, explaining $6.18-14.89 \%$ of the SL variation. QSI.cib-5B was a stable QTL and detected in three environments and the BLUP datasets, explaining $3.79-5.96 \%$ of the SL variation. Alleles of CM39 for the two QTLs contributed to increase of SL. Two minor QTLs QSI.cib-5A and QSI.cib-6A were detected in two or three environments, explaining $3.47-7.8 \%$ and $5.63-5.9 \%$ of the SL variation, respectively. The positive alleles of the two QTLs were contributed by CM42 (Table 2 ).

Four QTLs for SNS were identified on chromosomes 1B, 1D, 4A and 7A. Of them, QSns.cib-1B and QSns.cib-4A were detected in three environments and the BLUP datasets, explaining 7.47-16.18\% and $2.34-10.46 \%$ of the SNS variation, respectively. QSns.cib-1D and QSns.cib-7A were detected in two environments, explaining $6.77-8.39 \%$ and $5.06-8.18 \%$ of the SNS variation, respectively. The favorable alleles of $Q S n s . c i b-1 B$ and $Q S n s$.cib-7A were contributed by CM39, and that of QSns.cib-1D and QSns.cib-4A were contributed by CM42 (Table 2). 
Table 2 Quantitative trait loci (QTLs) for thousand grain weight (TGW), grain number per spike (GNS), grain width (GW), grain length (GL), plant height (PH), $\mathrm{s}$

\begin{tabular}{|c|c|c|c|c|c|c|}
\hline Trait & $Q T L$ & Environment & Chromosome & $\begin{array}{l}\text { Interval } \\
(\mathrm{cM})\end{array}$ & $\begin{array}{l}\text { Flanking } \\
\text { Markers }\end{array}$ & LOD \\
\hline \multirow[t]{2}{*}{ TGW } & $\begin{array}{l}\text { QTgw.cib- } \\
6 A .1\end{array}$ & 18SHF/18SHL/BLUP & $6 \mathrm{~A}$ & $\begin{array}{l}41.3- \\
42.46\end{array}$ & $\begin{array}{l}\text { Marker87546- } \\
\text { Marker87736 }\end{array}$ & $6.17 / 8.03 / 4.44$ \\
\hline & $\begin{array}{l}\text { QTgw.cib- } \\
6 A .2\end{array}$ & 17SHF/18SHL/19SHF/19SHL/BLUP & $6 \mathrm{~A}$ & $\begin{array}{l}52.98- \\
59.52\end{array}$ & $\begin{array}{l}\text { Marker90290- } \\
\text { Marker91587 }\end{array}$ & $9.48 / 7.95 / 7.27 / 1$ \\
\hline \multirow[t]{6}{*}{ GW } & $\begin{array}{l}Q G W . c i b- \\
2 A\end{array}$ & 18SHF/19SHF & $2 \mathrm{~A}$ & $\begin{array}{l}14.86- \\
17.08\end{array}$ & $\begin{array}{l}\text { Marker26336- } \\
\text { Marker26958 }\end{array}$ & $5.48 / 2.76$ \\
\hline & $\begin{array}{l}\text { QGW.cib- } \\
2 B .1\end{array}$ & 19SHF/19SHL & $2 \mathrm{~B}$ & $\begin{array}{l}39.6- \\
43.07\end{array}$ & $\begin{array}{l}\text { Marker29502- } \\
\text { Marker29525 }\end{array}$ & $2.66 / 4.09$ \\
\hline & $\begin{array}{l}\text { QGW.cib- } \\
2 B .2\end{array}$ & 17SHF/BLUP & $2 \mathrm{~B}$ & $\begin{array}{l}121.67- \\
121.93\end{array}$ & $\begin{array}{l}\text { Marker34419- } \\
\text { Marker34417 }\end{array}$ & $3.83 / 3.7$ \\
\hline & $\begin{array}{l}\text { QGW.cib- } \\
5 A\end{array}$ & 17SHF/BLUP & $5 \mathrm{~A}$ & $\begin{array}{l}27.76- \\
27.97\end{array}$ & $\begin{array}{l}\text { Marker70243- } \\
\text { Marker70216 }\end{array}$ & $3.91 / 4.73$ \\
\hline & $\begin{array}{l}\text { QGW.cib- } \\
6 A\end{array}$ & 17SHF/17SHL/18SHL/19SHF/19SHL/BLUP & $6 \mathrm{~A}$ & $\begin{array}{l}49.98- \\
58.87\end{array}$ & $\begin{array}{l}\text { Marker90210- } \\
\text { Marker91133 }\end{array}$ & 13.09/4.95/8.93, \\
\hline & $\begin{array}{l}Q G W \cdot c i b- \\
7 B\end{array}$ & 18SHF/19SHL & 7B & $\begin{array}{l}179.93- \\
180.13\end{array}$ & $\begin{array}{l}\text { Marker111000- } \\
\text { Marker110965 }\end{array}$ & $5.36 / 5.98$ \\
\hline \multirow[t]{6}{*}{$\mathrm{GL}$} & $\begin{array}{l}\text { QGl.cib- } \\
3 A\end{array}$ & 17SHF/17SHL/18SHL/19SHF/19SHL/BLUP & $3 \mathrm{~A}$ & $\begin{array}{l}64.7- \\
66.41\end{array}$ & $\begin{array}{l}\text { Marker40793- } \\
\text { Marker40901 }\end{array}$ & $5.31 / 2.97 / 6.1 / 5$ \\
\hline & $\begin{array}{l}\text { QGI.cib- } \\
5 A .1\end{array}$ & 17SHL/BLUP & $5 \mathrm{~A}$ & $\begin{array}{l}3.46- \\
7.55\end{array}$ & $\begin{array}{l}\text { Marker69377- } \\
\text { Marker69395 }\end{array}$ & $2.83 / 3.66$ \\
\hline & $\begin{array}{l}\text { QGI.cib- } \\
\text { 5A.2 }\end{array}$ & 18SHL/19SHF & $5 \mathrm{~A}$ & $\begin{array}{l}86.87- \\
87.49\end{array}$ & $\begin{array}{l}\text { Marker71923- } \\
\text { Marker71919 }\end{array}$ & $3.79 / 3.82$ \\
\hline & $\begin{array}{l}\text { QGI.cib- } \\
6 A\end{array}$ & 17SHF/18SHF/18SHL/19SHF/19SHL/BLUP & $6 \mathrm{~A}$ & $\begin{array}{l}42.36- \\
43.4\end{array}$ & $\begin{array}{l}\text { Marker87807- } \\
\text { Marker87738 }\end{array}$ & 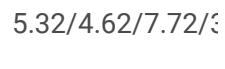 \\
\hline & $\begin{array}{l}\text { QGI.cib- } \\
6 D\end{array}$ & 18SHL/19SHF/BLUP & $6 \mathrm{D}$ & $\begin{array}{l}76.06- \\
83.69\end{array}$ & $\begin{array}{l}\text { Marker99119- } \\
\text { Marker99140 }\end{array}$ & $4.17 / 5 / 3.17$ \\
\hline & $\begin{array}{l}\text { QGI.cib- } \\
7 D\end{array}$ & 17SHF/17SHL/BLUP & 7D & $\begin{array}{l}32.68- \\
38.76\end{array}$ & $\begin{array}{l}\text { Marker111521- } \\
\text { Marker111597 }\end{array}$ & $3 / 4.64 / 6.19$ \\
\hline \multirow[t]{6}{*}{$\mathrm{PH}$} & $\begin{array}{l}\text { QPh.cib- } \\
1 A\end{array}$ & 16SHF/17SHL/19SHF & $1 \mathrm{~A}$ & $\begin{array}{l}28.34- \\
30.95\end{array}$ & $\begin{array}{l}\text { Marker5758- } \\
\text { Marker6328 }\end{array}$ & $5.58 / 6.07 / 3.64$ \\
\hline & $\begin{array}{l}Q P h . c i b- \\
2 D\end{array}$ & 16SHF/17SHL/18SHF/18SHL/19SHF/BLUP & $2 \mathrm{D}$ & $\begin{array}{l}1.48- \\
5.16\end{array}$ & $\begin{array}{l}\text { Marker35344- } \\
\text { Marker35422 }\end{array}$ & $3.42 / 4.31 / 3 / 4.7 /$ \\
\hline & $\begin{array}{l}\text { QPh.cib- } \\
4 A\end{array}$ & 16SHF/17SHL & $4 \mathrm{~A}$ & $\begin{array}{l}82.78- \\
83.05\end{array}$ & $\begin{array}{l}\text { Marker57956- } \\
\text { Marker57959 }\end{array}$ & $4.76 / 5.71$ \\
\hline & $\begin{array}{l}\text { QPh.cib- } \\
5 A\end{array}$ & 17SHF/19SHL/BLUP & $5 \mathrm{~A}$ & $\begin{array}{l}126.27- \\
126.52\end{array}$ & $\begin{array}{l}\text { Marker72631- } \\
\text { Marker72950 }\end{array}$ & $3.02 / 2.91 / 2.52$ \\
\hline & $\begin{array}{l}\text { QPh.cib- } \\
5 B\end{array}$ & 16SHF/17SHL & $5 B$ & $\begin{array}{l}134.43- \\
134.74\end{array}$ & $\begin{array}{l}\text { Marker83905- } \\
\text { Marker83879 }\end{array}$ & $3.07 / 3.18$ \\
\hline & $\begin{array}{l}\text { QPh.cib- } \\
6 A\end{array}$ & 16SHF/17SHL/19SHF & $6 \mathrm{~A}$ & $\begin{array}{l}54.61- \\
54.76\end{array}$ & $\begin{array}{l}\text { Marker90459- } \\
\text { Marker90388 }\end{array}$ & $6.13 / 8.86 / 5.6$ \\
\hline \multirow[t]{2}{*}{ GNS } & $\begin{array}{l}\text { QGns.cib- } \\
2 D\end{array}$ & 18SHF/19SHF/BLUP & $2 \mathrm{D}$ & $0-5.16$ & $\begin{array}{l}\text { Marker35164- } \\
\text { Marker35422 }\end{array}$ & $2.57 / 2.63 / 4.73$ \\
\hline & $\begin{array}{l}\text { QGns.cib- } \\
6 A\end{array}$ & 18SHL/19SHF/BLUP & $6 \mathrm{~A}$ & $\begin{array}{l}56.45- \\
59.52\end{array}$ & $\begin{array}{l}\text { Marker90628- } \\
\text { Marker91587 }\end{array}$ & $3.35 / 3.83 / 4.91$ \\
\hline \multirow[t]{4}{*}{ SL } & $\begin{array}{l}\text { QSl.cib- } \\
2 D\end{array}$ & 16SHF/16SHL/17SHF/17SHL/18SHF/18SHL/19SHF/19SHL/BLUP & $2 \mathrm{D}$ & $\begin{array}{l}1.48- \\
5.16\end{array}$ & $\begin{array}{l}\text { Marker35344- } \\
\text { Marker35422 }\end{array}$ & $3.42 / 6.86 / 6.82 / \varepsilon$ \\
\hline & $\begin{array}{l}\text { QSI.cib- } \\
5 A\end{array}$ & 18SHL/19SHF/BLUP & $5 \mathrm{~A}$ & $\begin{array}{l}17.71- \\
21.48\end{array}$ & $\begin{array}{l}\text { Marker69427- } \\
\text { Marker69525 }\end{array}$ & $2.59 / 6 / 2.61$ \\
\hline & $\begin{array}{l}\text { QSl.cib- } \\
5 B\end{array}$ & 16SHF/16SHL/17SHF/BLUP & $5 B$ & $\begin{array}{l}40.07- \\
40.38\end{array}$ & $\begin{array}{l}\text { Marker81580- } \\
\text { Marker81513 }\end{array}$ &  \\
\hline & $\begin{array}{l}\text { QSI.cib- } \\
6 A\end{array}$ & 19SHF/BLUP & $6 \mathrm{~A}$ & $\begin{array}{l}58.87- \\
64.37\end{array}$ & $\begin{array}{l}\text { Marker91133- } \\
\text { Marker91933 }\end{array}$ & $4.62 / 3$ \\
\hline
\end{tabular}

PVE; mean of phenotypic variation explained; $L O D$, logarithm of the odd; Add, mean of additive effect (Positive values indicate that alleles from CM39 are inc prediction. 


\begin{tabular}{|c|c|c|c|c|c|c|}
\hline Trait & QTL & Environment & Chromosome & $\begin{array}{l}\text { Interval } \\
\text { (cM) }\end{array}$ & $\begin{array}{l}\text { Flanking } \\
\text { Markers }\end{array}$ & LOD \\
\hline \multirow[t]{4}{*}{ SNS } & $\begin{array}{l}\text { QSns.cib- } \\
\text { IB }\end{array}$ & 17SHF/18SHL/19SHF/BLUP & 1B & $\begin{array}{l}28.8^{-} \\
33.3\end{array}$ & $\begin{array}{l}\text { Marker15740- } \\
\text { Marker17413 }\end{array}$ & 16.86/4.13/6.11, \\
\hline & $\begin{array}{l}\text { QSns.cib- } \\
\text { TD }\end{array}$ & 17SHL/BLUP & 1D & $\begin{array}{l}146.67- \\
148.82\end{array}$ & $\begin{array}{l}\text { Marker23471- } \\
\text { Marker23475 }\end{array}$ & $5.65 / 4.49$ \\
\hline & $\begin{array}{l}\text { QSns.cib- } \\
4 A\end{array}$ & 17SHF/18SHL/19SHF/BLUP & $4 \mathrm{~A}$ & $\begin{array}{l}72.98- \\
81.71\end{array}$ & $\begin{array}{l}\text { Marker57882- } \\
\text { Marker57915 }\end{array}$ & 2.51/4.94/5.3/5 \\
\hline & $\begin{array}{l}\text { QSns.cib- } \\
7 A\end{array}$ & 19SHF/19SHL & $7 \mathrm{~A}$ & $\begin{array}{l}81.76- \\
85.42\end{array}$ & $\begin{array}{l}\text { Marker103527- } \\
\text { Marker103903 }\end{array}$ & $3.25 / 4.47$ \\
\hline
\end{tabular}

$P V E$; mean of phenotypic variation explained; $L O D$, logarithm of the odd; Add, mean of additive effect (Positive values indicate that alleles from CM39 are inc prediction.

\section{Effects of major QTL in mapping populations}

Six major QTLs QSI.cib-2D, QGI.cib-3A, QTgw.cib-6A.1, QTgw.cib-6A.2, QGw.cib-6A, and QGI.cib-6A were stably identified in multiple environments and the BLUP datasets (Table 2). We further analyzed their effect on corresponding traits based on the flanking markers in the CM42×CM39 RIL population. As expected, lines possessing the positive alleles of the six loci showed significantly better performance on the corresponding traits compared with those have alleles showing negative effects in all environments and the BLUP datasets (Fig. 2). Additionally, three Kompetitive Allele Specific PCR (KASP) markers linked with QTgw.cib-6A.1, QTgw.cib-6A.2, QGw.cib-6A, QGI.cib-6A, and QSI.cib-2D were developed in the present study, which could be utilized in MAS for wheat yield improvement (Table S3, Figure S1).

\section{QTL clusters on chromosome 2D and 6A}

The QTL cluster on 2D, including three QTLs QSI.cib-2D, QPh.cib-2D and QGns.cib-2D, was co-located between Marker35164 and Marker35422 (Table 2). The CM39 alleles at the locus contributed to longer spike and higher plant, but less GNS. Two QTL clusters were identified on chromosome 6A (Table 2). One comprised two QTLs, QTgw.cib-6A.1 and QGI.cib-6A, was located between Marker87546 and Marker87738. The alleles of CM42 at the locus contributed to increased grain length and weight (Table 2). The other one contained five QTLs, QTgw.cib-6A.2, QGw.cib-6A, QPh.cib-6A, QGns.cib-6A and QSI.cib-6A, was located between Marker90210 and Marker91587. The allele of CM39 at the locus contributed to higher TGW, GW, PH and SL, but less GNS (Table 2).

\section{Discussion}

\section{QTL analysis and comparison with previous studies}

Wheat yield components are significantly associated with yield and typically show higher heritability than the yield itself, and thus, mining the genes or QTLs related to yield components will be help for elucidating the genetic basis of wheat yield and facilitating the genetic improvement of varieties with high yield [5-7]. In the present study, a RIL population derived from two elite winter wheat varieties were used to dissect the genetic basis of variation for seven yield components, including TGW, GNS, GW, GL, PH, SL and SNS. A total of 30 QTLs were identified in multiple environments, explaining 2.34-23.75\% of the phenotypic variance.

Fourteen QTLs were identified for grain size and weight, including two for TGW, six for GW and six for GL. Among them, QTgw.cib-6A.1 and QGl.cib-6A were colocated on chromosome arm 6AS, which was near to QTkw-6A. 1 and QTgw.cau-6A.4[1,30]. QTgw.cib-6A.2 was located on chromosome arm 6AL and near to QTKW.caas-6AL and QTKW-6A.1 [31, 32]. The QTL QGW.cib-6A for GW was located in a large interval on chromosome 6A. This interval near to a known gene TaGW2 controlling TGW and GW [33, 34]. QGW.cib-2A on chromosome 2A was overlapped with QGwt.crc-2A detected by McCartney et al [35]. QGw.cib-2B.1 on chromosome 2B was overlapped with qKW2B-1 detected by Xin et al [23]. QGw.cib-7B on chromosome 7B was located near to a QTL for TGW QTgw.wa-7BL [6]. Two QTLs for GL QGI.cib-3A and QGI.cib-5A.1 on chromosomes 3A and 5A, respectively, were overlapped with two QTLs for GL detected by Mohler et al [36]. QGI.cib-5A.2 was near to a QTL for TGW QTKW.ndsu.5A. 1 reported previously [34]. QGI.cib-7D was overlapped with QGI.cau-7D detected by Yan et al [37]. For the rest three QTLs QGw.cib-2B.2, QGw.cib-5A and QGI.cib-6D, no stable QTL for grain size reported previously was overlapped with them, indicating they were likely novel QTL (Table. 3).

PH and SL are important traits related to plant architecture and yield potential in wheat $[12,38]$. In the present study, six and four QTLs for PH and SL were identified, respectively. Among them, $Q P$ h.cib-2D and $Q S I . c i b-2 D$ were co-located in the same interval on chromosome arm 2DS, which was overlapped with the dwarfing gene Rht8 [24, 39]. QPh.cib-4A and QPh.cib-5A were located near to two loci for PH reported by Luján Basile et al [40]. QPh.cib-6A on chromosome 6A was overlapped with the dwarfing gene Rht18 [41]. QSI.cib-5A on chromosome 5A was located near to QSL5A.3 detected by Liu et al [42]. For the rest four QTLs QPh.cib-1A, QPh.cib-5B, QSI.cib-5B and QSI.cib-6A, no stable QTL for PH and SL reported previously was overlapped with them, indicating they were likely novel (Table. 3).

Additionally, two QTLs for GNS and four QTLs for SNS were identified in the present study. Of them, QGns.cib-2D were co-located with QPh.cib-2D and QSI.cib2D on chromosome 2D and overlapped with the dwarfing gene Rht8 [24, 39]. QGns.cib-6A was co-loctaed with QTgw.cib-6A.2 and near to two QTLs for TGW QTKW.caas-6AL and QTKW-6A.1 [31, 32]. QSns.cib-1B for SNS on chromosome 1B was overlapped with the QSn.sau-1BL reported recently [5]. QSns.cib-7A for SNS on chromosome 7A was overlapped with QSn-7A.2 detected by Cao et al [43]. For the rest two QTLs QSns.cib-1D and QSns.cib-4A, no stable QTL for SNS reported previously was overlapped with them, indicating they were likely novel (Table. 3). 
Table 3

The physical interval of QTLs detected in the present study and comparison with QTLs previously reported.

\begin{tabular}{|c|c|c|c|c|c|}
\hline Traits & $Q T L s$ & Chromosomes & Physical position (Mb) & Nearby known locus & References \\
\hline \multirow[t]{2}{*}{ TGW } & QTgw.cib-6A.1 & $6 \mathrm{~A}$ & $73.08-82.67$ & QTkw-6A.1, QTgw.cau-6A.4 & {$[1,30]$} \\
\hline & QTgw.cib-6A.2 & $6 \mathrm{~A}$ & $442.82-554.21$ & QTKW.caas-6AL, QTKW-6A.1 & {$[31,32]$} \\
\hline \multirow[t]{6}{*}{ GW } & QGw.cib-2A & $2 \mathrm{~A}$ & $517.02-581.44$ & QGwt.crc-2A & [35] \\
\hline & QGw.cib-2B.1 & $2 B$ & $150.75-151.74$ & $q K W 2 B-1$ & [23] \\
\hline & QGw.cib-2B.2 & $2 \mathrm{~B}$ & $734.72-734.72$ & & \\
\hline & QGw.cib-5A & $5 \mathrm{~A}$ & 202.92-212.92 & & \\
\hline & QGw.cib-6A & $6 \mathrm{~A}$ & $422.35-537.67$ & TaGW2 & {$[33,34]$} \\
\hline & QGW.cib-7B & 7B & 735.93-740.06 & QTgw.wa-7BL & [6] \\
\hline \multirow[t]{6}{*}{$\mathrm{GL}$} & QGI.cib-3A & $3 \mathrm{~A}$ & 659.71-668.09 & IWA4298-IWB11347 & [36] \\
\hline & QGI.cib-5A.1 & $5 \mathrm{~A}$ & $26.14-29.28$ & IWA4871-IWB34408 & [36] \\
\hline & QGI.cib-5A.2 & $5 \mathrm{~A}$ & $453.5-453.6$ & QTKW.ndsu.5A.1 & [34] \\
\hline & QGl.cib-6A & $6 \mathrm{~A}$ & 79.99-82.67 & & \\
\hline & QGI.cib-6D & $6 \mathrm{D}$ & $75.08-83.92$ & & \\
\hline & QGI.cib-7D & 7D & $66.19-107.61$ & QGI.cau-7D & [37] \\
\hline \multirow[t]{6}{*}{$\mathrm{PH}$} & QPh.cib-1A & $1 \mathrm{~A}$ & $345.37-443.28$ & & \\
\hline & QPh.cib-2D & $2 \mathrm{D}$ & $20.68-29.35$ & Rht8, QPLH-2D & {$[24,39,55]$} \\
\hline & QPh.cib-4A & $4 \mathrm{~A}$ & $704.53-704.58$ & Chr4A-B57-Нар6 & {$[40]$} \\
\hline & QPh.cib-5A & $5 \mathrm{~A}$ & $501.62-523.22$ & Chr5A-B54-Нар3 & {$[40]$} \\
\hline & QPh.cib-5B & $5 \mathrm{~B}$ & $607.07-608.06$ & & \\
\hline & QPh.cib-6A & $6 \mathrm{~A}$ & $447.77-451.27$ & Rht18 & [41] \\
\hline \multirow[t]{2}{*}{ GNS } & QGns.cib-2D & $2 \mathrm{D}$ & 8.4-29.35 & Rht8 & {$[24,39]$} \\
\hline & QGns.cib-6A & $6 \mathrm{~A}$ & $471.16-554.21$ & QTKW.caas-6AL, QTKW-6A.1 & {$[31,32]$} \\
\hline \multirow[t]{4}{*}{ SL } & QSI.cib-2D & $2 \mathrm{D}$ & $20.68-29.35$ & Rht8, QPLH-2D & {$[24,39,55]$} \\
\hline & QSI.cib-5A & $5 \mathrm{~A}$ & $35.84-45.91$ & QSL5A.3 & [42] \\
\hline & QSI.cib-5B & $5 B$ & $404.42-406.31$ & & \\
\hline & QSI.cib-6A & $6 \mathrm{~A}$ & $537.67-584$ & & \\
\hline \multirow[t]{4}{*}{ SNS } & QSns.cib-1B & 1B & $381.92-439.8$ & QSn.sau-1BL & [5] \\
\hline & QSns.cib-1D & $1 \mathrm{D}$ & $482.32-485.76$ & & \\
\hline & QSns.cib-4A & $4 \mathrm{~A}$ & 691.53-703.17 & & \\
\hline & QSns.cib-7A & $7 \mathrm{~A}$ & $524.95-562.63$ & QSn-7A.2 & [43] \\
\hline
\end{tabular}

\section{QTL cluster on chromosomes 2D and 6A}

Numerous co-located QTLs associated with multiple traits have been reported in previous studies $[2,5,17,44,45]$, which are beneficial to improve breeding efficiency for multiple elite traits, and thus is favorable for pyramiding breeding or MAS. In the present study, three QTLs QSI.cib-2D, QPh.cib-2D and QGns.cib$2 D$ were co-located in the interval of 8.4-29.35 Mb on chromosome arm 2DS (Table 3). The allele of CM42 at the locus decreases SL and PH while increasing GNS. Additionally, the locus was overlapped with the dwarfing gene Rht8, which has been reported to associated with QTLs for PH, SL, SNS, GNS, spikelet compactness, TGW, and grain yield [12,39, 46-48]. Interestingly, no QTL for grain size and weight detected in the present study was overlapped with the locus, indicating it had no effect on grain size and weight. Given CM42 was bred by utilizing synthetic wheat germplasm [49], further studies, such as fine-mapping and map-based cloning are needed to future reveal the relationship between the locus and Rht8. However, the results in this study showed that the locus could be utilized in optimization $\mathrm{PH}$ with no penalty for grain size and weight in MAS.

Two QTL clusters were detected on chromosome 6A in the present study. One harbored two QTLs for TGW and GL with overlapped intervals on chromosome arm 6AS (Table 2), indicating the locus increases TGW by mainly increasing GL. The other one comprised five QTLs for TGW, GW, GNS, PH and SL overlapped on chromosome arm 6AL (Table 2), indicating the locus increases TGW by mainly increasing GW. However, interval of the QTL cluster on chromosme 6AL were large and near to TaGW2 and Rht18 [41,50,51]. Therefore, additional populations may be needed to dissect the relationships of them. 
To date, numerous QTL for wheat yield and yield components have been identified on all wheat chromosomes [3, 21, 52-54]. However, due to the negative correlation between GNS and TGW, a challenge must being faced during increasing yield is how to optimize the trade-off between GNS and TGW by choosing suitable QTLs in breeding practice [2]. In the present study, three major QTLs, QPh/SI.cib-2D, QGI.cib-3A and QTgw.cib-6A.2 were selected to explore the balance of TGW and GNS. As showed in the Table 4, lines possessing the allele form CM42 at the three loci have relatively higher TGW and GNS, which might partly explain the high yield of CM42. Additionally, lines possessing the allele from CM42 at $Q P h / S l . c i b-2 D$ and $Q T g w . c i b-6 A .2$ and the allele from CM39 at QGl.cib-3A also have relatively higher TGW and GNS. However, for the other combination schemes, either the higher TGW but lower GNS, or higher GNS but lower TGW, or both lower TGW and GNS were harvested. Overall, the QTLs and KASP markers in this study will be useful for elucidating the genetic architecture of grain yield and developing new wheat varieties with high and stable yield in wheat.

Table 4

Haplotype analysis for three major QTLs QPh/SI.cib-2D, QGI.cib-3A and QTgw.cib-6A.2 in the CM42×CM39 RILs.

\begin{tabular}{|c|c|c|c|}
\hline Haplotypes & Lines & TGW(g) ${ }^{* *}$ & GNS * \\
\hline aabbcc & 20 & $46.97 \pm 2.85^{\mathrm{a}}$ & $52.25 \pm 5.25^{\mathrm{cd}}$ \\
\hline $\mathrm{AABBcC}$ & 14 & $47.63 \pm 3.29 \mathrm{a}$ & $49.78 \pm 5.12 \mathrm{abc}$ \\
\hline AAbbcc & 7 & $49.75 \pm 3.76^{a b}$ & $55.2 \pm 5.51 d$ \\
\hline aaBBcc & 16 & $51.53 \pm 2.42^{b c}$ & $50.58 \pm 3.48 b c$ \\
\hline aabbcc & 20 & $53.13 \pm 3.49 \mathrm{~cd}$ & $47.74 \pm 4.1^{\mathrm{a}}$ \\
\hline AAbbCc & 18 & $53.17 \pm 2.17 \mathrm{~cd}$ & $50.58 \pm 4$ bc \\
\hline aaBBCC & 21 & $54.25 \pm 2.94^{d}$ & $48.84 \pm 3.47^{a b}$ \\
\hline AABBCC & 31 & $53.32 \pm 2.88^{d}$ & $50.07 \pm 2.86^{b c}$ \\
\hline
\end{tabular}

\section{Potential candidate genes for QTgw.cib-6A.1/QGI.cib-6A and QGI.cib-3A}

Among these major QTL, QSI.cib-2D was likely allele with Rht8. In the previous study, TraesCS2D01G055700 was reported by Chai et al [55] as a possible candidate gene for Rht8. QTgw.cib-6A.2 and QGW.cib-6A needed additional populations to narrow their intervals. Therefore, we mainly analyzed possible candidates for QTgw.cib-6A.1/QGI.cib-6A and QGI.cib-3A in the present study.

QTgw.cib-6A.1 and QGI.cib-6A were co-loctaed between 73.08 and $82.67 \mathrm{Mb}$ on CS chromosome 6A, and QGI.cib-3A was located between 659.71 and 668.09 Mb on CS chromosme 3A (Table 3). In the interval of QTgw.cib-6A.1/QGI.cib-6A and QGI.cib-3A, there were 81 and 85 predicted genes in the CS genome, respectively. Expression pattern analyses showed that 45 and 57 genes in the interval of QTgw.cib-6A.1/QGl.cib-6A and GI.cib-3A expressed in various tissue, respectively (Fig. 3, Table S4, Table S5) [56, 57]. Among them, several were abundantly expressed in grain, indicating they are likely associated with grain growth and development (Fig. 3). For example, TraesCS6A02G107800 is an ortholog of the rice RGG2 and encodes a guanine nucleotide-binding protein subunit gamma 2 (Table S4). Miao et al [58] previously reported that $R G G 2$ played a negative role in plant growth and yield production and that manipulation of $R G G 2$ can increase the plant biomass, grain weight, length and yield in rice. TraesCS6A02G112400 andTraesCS3A02G424000 encode polyubiquitin and small ubiquitin-related modifier, respectively (Table S4, Table S5). TraesCS3A02G421900 encodes a 26S proteasome regulatory subunit (Table S5), which participates in the ubiquitin/26S proteasome pathway and mediate the degradation of the complex of ubiquitin receptor and polyubiquitinated protein [59,60]. Previous studies reveled that the ubiquitin pathway play a important role in regulation grain size and weight in rice [61, 62]. These results indicated that the four genes were likely closely related to grain size and weight in wheat and they were useful in our following work of fne mapping and cloning of $Q T g w . c i b-$ 6A.1/QGI.cib-6A and QGI.cib-3A.

\section{Conclusion}

In this study, a total of 30 QTLs for TGW, GNS, GW, GL, PH, SL, and SNS were identified, explaining 2.34-23.75\% of the phenotypic variance. Among them, six major QTLs QTgw.cib-6A.1, QTgw.cib-6A.2, QGw.cib-6A, QGI.cib-3A, QGI.cib-6A, and QSI.cib-2D showed strong and stable effects on corresponding traits in different environments and the BLUP datasets. Three KASP markers linked with five of these major QTLs were developed. These QTLs and KASP markers will be useful for elucidating the genetic architecture of grian yield and developing new wheat varieties with high and stable yield in wheat. Additonally, candidate genes of QTgW.cib-6A.1/QGI.cib-6A and QGI.cib-3A were preliminary analyzed.

\section{Methods}

\section{Plant materials and field trials}

A RIL population $\left(\mathrm{F}_{10}\right)$ comprising 193 lines derived from a cross CM42 and CM39 was used for QTL detection in the present study, which were developed by our laboratory in Chengdu Institute of Biology (CIB). CM42 is the first wheat elite variety in the world bred by using synthetic hexaploid wheat (Triticum turgidum $\times$ Aegilops tauschii) germplasm, and showed high yield potential in Sichuan and the Yangzi River region [49], while CM39 is a elite winter wheat

Page 10/17 
variety with different genetic background to that of CM42. CM42 and CM39 seeds were obtained from Sichuan Academy of Agricultural Sciences (SAAS). The RIL population and their parents were evaluated at two experimental sites in Sichuan province of China, Shuangliu (SHL, $\left.103^{\circ} 52^{\prime} \mathrm{E}, 30^{\circ} 34^{\prime} \mathrm{N}\right)$ and $\mathrm{Shifang}(\mathrm{SHF}$, $104^{\circ} 11^{\prime} \mathrm{E}, 31^{\circ} 6^{\prime} \mathrm{N}$ ), during four growing seasons from 2015-2016 to 2018-2019. Randomized block design was adopted for all of the trials. Each line was planted in a one-row plot with 50 seeds per row, a row length of $2.0 \mathrm{~m}$, and a row spacing of $0.3 \mathrm{~m}$. Five replicates were performed under each environment. Nitrogen and superphosphate fertilizers were applied at a rate of 80 and $100 \mathrm{~kg} / \mathrm{ha}$, respectively, at sowing. Crop management and disease control were performed according to local cultivation practices.

\section{Phenotyping and statistical analysis}

At maturity, ten representative plants from middle row of each line were randomly selected to investigate agronomic traits including TGW, GL, GW, GNS, PH, SL and SNS. SL was measured as the length from the base of the rachis to the tip of the terminal spikelet, excluding the awns. SNS was determined by counting the number of spikelets in main spikes; PH was measured from the soil surface to the tip of the spike, excluding the awns. Subsequently, the main spike of all selected plants were harvested and manually threshed for evaluating GNS, TGW, GW and GL using SC-G software (Wseen Co., Ltd, China). PH and SL were evaluated in eight environments, and the rest traits were evaluated in six environments.

Basic phenotypic statistical analyses, frequency distribution, correlation analyses and student's t tests were performed with SPSS version 20.0 (Chicago, IL, USA). The phenotype distribution graph was drawn using the plugin "CorrPlot" in Tbtools [63]. The relationships among measured traits were visualized using the R package "qgraph". The BLUP dataset across evaluated environments was calculated using the "Imer" function implemented in R package "Ime4". The broad sense heritability (H2) was estimated using the PROC GLM procedure in SAS (SAS Institute Inc., North Carolina, USA) based on the following equation: where is the variance of genotypes, is the variance of genotype by environmental effect, is the residual variance, $n$ is the number of environments and $r$ is the number of replicates [64].

\section{Linkage map construction and QTL detection}

A whole-genome genetic map constructed previously was adopted for QTL mapping [29]. The genetic map was constructed using the CM42×CM39 RIL population with SALF markers. A total of 4996 Bin SLAFs were distributed in 21 linkage groups and covered a total genetic distance of 2,859.94 cM with an average interval of $0.57 \mathrm{cM}$ between adjacent Bin marker (Table S1) [29].

QTL analysis was conducted using the inclusive composite interval mapping (ICIM) function of IciMapping 4.1 (https://www.isbreeding.net) with the minimal LOD score was set at 2.5. The missing phenotype was deleted in QTL analysis. QTL was named according to the provision of Genetic Nomenclature (http://wheat.pw.usda.gov/ggpages/wgc/98/Intro.htm), where 'ClB' represents Chengdu Institute of Biology.

\section{Prediction of candidate gene}

Flanking markers for each QTL were blasted against the Chinese Spring (CS) reference genome sequence (RefSeq v1.0) published by the International Wheat Genome Sequencing Consortium (IWGSC; https://wheat-urgi.versailles.inra.fr/) to confirm their physical positions [65, 66]. Genes between flanking markers were extracted from IWGSC RefSeq v1.1 annotation for CS (https://wheat-urgi.versailles.inra.fr/). The annotations and functions of a given gene were analyzed using UniProt (https://www.uniprot.org/). The expression pattern analysis was performed by using Wheat Expression Browser (http://www.wheatexpression.com/), and the circle graph of expression values was drawn using Tbtools [63]. The orthologous gene analysis between wheat and rice was conducted using the Triticeae-Gene Tribe (http://wheat.cau.edu.cn/TGT/) [67].

\section{List of abbreviations}

CM42: Chuanmai42; CM39: Chuanmai39; SHF: Shifang; SHL: Shuangliu; TGW:Thousand grain weight; GNS: Grain number per spike; GW: Grain width; GL: Grain length; PH: Plant height; SL: Spike length; SNS: Spikelet number per spike; QTL: Quantitative trait loci; SALF: Specific-locus amplifed fragment; MAS: Marker-assisted selection; KASP: Kompetitive Allele Specific PCR; BLUP: Best linear unbiased prediction

\section{Declarations}

\section{Funding}

This work is supported by National Key R\&D Program of China (2016YFD0100102), Strategic Priority Research Program of the Chinese Academy of Sciences (Grant No. XDA08020205), Science and Technology Support Project of Sichuan Province, China (2016NZ0103), Key Project of Crop Breeding of Sichuan Province (2016NYZ0030), and Science and technology projects of Sichuan Province (2020YFSY0049).

\section{Conflict of interest}

All authors declare that they have no conflict of interest.

\section{Ethics approval}

The authors declare that this research has no human and animal participants and that the experiments comply with the current laws of China.

\section{Consent to participate}

Not applicable

\section{Consent for publication}


Not applicable

Availability of data and material

\section{All data used in this study was present in the manuscript and supporting materials.}

\section{Code availability}

Not applicable.

Author contributions statement

TL undertook the field trials and subsequent analysis of all available data including the phenotyping and population genotyping, and drafted this manuscript. QL and ZP undertook the genetic map constructed. JW, ZY, YT, YS, JZ, XQ and XP participated in phenotyping. ZL, WY and JLprovided us the CM42 and CM39 seeds. MY, JL and HZ discussed results. HL, GD and YW designed the experiments, guided the entire study, participated in data analysis, discussed results and revised the manuscript. All authors have read and approved the manuscript.

\section{References}

1. Guan, P.; Lu, L.; Jia, L.; Kabir, M.R.; Zhang, J.; Lan, T.; Zhao, Y.; Xin, M.; Hu, Z.; Yao, Y.; et al. Global QTL Analysis Identifies Genomic Regions on Chromosomes 4A and 4B Harboring Stable Loci for Yield-Related Traits Across Different Environments in Wheat (Triticum aestivum L.). Front. Plant Sci. 2018, 9, doi:10.3389/fpls.2018.00529.

2. Isham, K.; Wang, R.; Zhao, W.; Wheeler, J.; Klassen, N.; Akhunov, E.; Chen, J. QTL mapping for grain yield and three yield components in a population derived from two high-yielding spring wheat cultivars. Theor. Appl. Genet. 2021, doi:10.1007/s00122-021-03806-1.

3. Li, T.; Deng, G.; Tang, Y.; Su, Y.; Wang, J.; Cheng, J. Identification and Validation of a Novel Locus Controlling Spikelet Number in Bread Wheat (Triticum aestivum L.). Front Plant Sci 2021, 12, 1-14, doi:10.3389/fpls.2021.611106.

4. Cui, F.; Ding, A.; Li, J.; Zhao, C.; Wang, L.; Wang, X.; Qi, X.; Li, X.; Li, G.; Gao, J. \%J E. QTL detection of seven spike-related traits and their genetic correlations in wheat using two related RIL populations. Euphytica 2012, 186, 177-192, doi:10.1007/s10681-011-0550-7

5. Ren, T.; Fan, T.; Chen, S.; Li, C.; Chen, Y.; Ou, X.; Jiang, Q.; Ren, Z.; Tan, F.; Luo, P.; et al. Utilization of a Wheat55K SNP array-derived high-density genetic map for high-resolution mapping of quantitative trait loci for important kemel-related traits in common wheat. Theor. Appl. Genet. 2021, 134, 807-821, doi:10.1007/s00122-020-03732-8.

6. Wang, J.; Liu, W.; Wang, H.; Li, L.; Wu, J.; Yang, X.; Li, X.; Gao, A. QTL mapping of yield-related traits in the wheat germplasm 3228. Euphytica 2011, 177, 277-292, doi:10.1007/s10681-010-0267-z.

7. Zhou, Y.; Conway, B.; Miller, D.; Marshall, D.; Cooper, A.; Murphy, P.; Chao, S.; Brown-Guedira, G.; Costa, J. Quantitative Trait Loci Mapping for Spike Characteristics in Hexaploid Wheat. Plant Genome 2017, 10, 1-15, doi:10.3835/plantgenome2016.10.0101.

8. Ellis, M.H.; Spielmeyer, W.; Gale, K.R.; Rebetzke, G.J.; Richards, R.A. "Perfect" markers for the Rht-B1b and Rht-D1b dwarfing genes in wheat. Theor. Appl. Genet. 2002, 105, 1038-1042, doi:10.1007/s00122-002-1048-4.

9. Lv, C.; Song, Y.; Gao, L.; Yao, Q.; Zhou, R.; Xu, R.; Jia, J. Integration of QTL detection and marker assisted selection for improving resistance to Fusarium head blight and important agronomic traits in wheat. Crop J. 2014, 2, 70-78, doi:10.1016/j.cj.2013.10.004.

10. Du, Y.; Chen, L.; Wang, Y.; Yang, Z.; Saeed, I.; Daoura, B.G.; Hu, Y.G. The combination of dwarfing genes Rht4 and Rht8 reduced plant height, improved yield traits of rainfed bread wheat (Triticum aestivum L.). F. Crop. Res. 2018, 215, 149-155, doi:10.1016/j.fcr.2017.10.015.

11. Fan, X.; Cui, F.; Ji, J.; Zhang, W.; Zhao, X.; Liu, J.J.; Meng, D.; Tong, Y.; Wang, T.; Li, J. Dissection of pleiotropic QTL regions controlling wheat spike characteristics under different nitrogen treatments using traditional and conditional QTL mapping. Front. Plant Sci. 2019, 10, 1-13, doi:10.3389/fpls.2019.00187.

12. Zhai, H.; Feng, Z.; Li, J.; Liu, X.; Xiao, S.; Ni, Z.; Sun, Q. QTL analysis of spike morphological traits and plant height in winter wheat (Triticum aestivum L.) using a high-density SNP and SSR-based linkage map. Front. Plant Sci. 2016, 7, 1-13, doi:10.3389/fpls.2016.01617.

13. Yang, Z.; Bai, Z.; Li, X.; Wang, P.; Wu, Q.; Yang, L.; Li, L.; Li, X. SNP identification and allelic-specific PCR markers development for TaGW2, a gene linked to wheat kernel weight. Theor. Appl. Genet. 2012, 125, 1057-1068, doi:10.1007/s00122-012-1895-6.

14. Gegas, V.C.; Nazari, A.; Griffiths, S.; Simmonds, J.; Fish, L.; Orford, S.; Sayers, L.; Doonan, J.H.; Snape, J.W. A genetic framework for grain size and shape variation in wheat. Plant Cell 2010, 22, 1046-1056, doi:10.1105/tpc.110.074153.

15. Cheng, X.; Xin, M.; Xu, R.; Chen, Z.; Cai, W.; Chai, L.; Xu, H.; Jia, L.; Feng, Z.; Wang, Z.; et al. A single amino acid substitution in STKc_GSK3 kinase conferring semispherical grains and its implications for the origin of triticum sphaerococcum[open]. Plant Cell 2020, 32, 923-934, doi:10.1105/TPC.19.00580.

16. Chen, Y.; Yan, Y.; Wu, T.T.; Zhang, G.L.; Yin, H.; Chen, W.; Wang, S.; Chang, F.; Gou, J.Y. Cloning of wheat keto-acyl thiolase 2B reveals a role of jasmonic acid in grain weight determination. Nat. Commun. 2020, 11, doi:10.1038/s41467-020-20133-z.

17. Cao, S.; Xu, D.; Hanif, M.; Xia, X.; He, Z. Genetic architecture underpinning yield component traits in wheat. Theor. Appl. Genet. 2020, 133, 1811-1823, doi:10.1007/s00122-020-03562-8.

18. Okamoto, Y.; Nguyen, A.T.; Yoshioka, M.; lehisa, J.C.M.; Takumi, S. Identification of quantitative trait loci controlling grain size and shape in the D genome of synthetic hexaploid wheat lines. Breed. Sci. 2013, 63, 423-429, doi:10.1270/jsbbs.63.423.

Page 12/17 
19. Marza, F.; Bai, G.H.; Carver, B.F.; Zhou, W.C. Quantitative trait loci for yield and related traits in the wheat population Ning7840 x Clark. Theor. Appl. Genet. 2006, 112, 688-698, doi:10.1007/s00122-005-0172-3.

20. Liu, T.; Wu, L.; Gan, X.; Chen, W.; Liu, B.; Fedak, G.; Cao, W.; Chi, D.; Liu, D.; Zhang, H.; et al. Mapping quantitative trait loci for 1000-grain weight in a double haploid population of common wheat. Int. J. Mol. Sci. 2020, 21, doi:10.3390/ijms21113960.

21. Li, X.; Xia, X.; Xiao, Y.; He, Z.; Wang, D.; Trethowan, R.; Wang, H.; Chen, X. QTL mapping for plant height and yield components in common wheat under water-limited and full irrigation environments. Crop Pasture Sci. 2015, 66, 660-670, doi:10.1071/CP14236.

22. Su, Q.; Zhang, X.; Zhang, W.; Zhang, N.; Song, L.; Liu, L.; Xue, X.; Liu, G.; Liu, J.; Meng, D.; et al. QTL Detection for Kernel Size and Weight in Bread Wheat (Triticum aestivum L.) Using a High-Density SNP and SSR-Based Linkage Map. Front. Plant Sci. 2018, 9, 1-13, doi:10.3389/fpls.2018.01484.

23. Xin, F.; Zhu, T.; Wei, S.; Han, Y.; Zhao, Y.; Zhang, D.; Ma, L.; Ding, Q. QTL Mapping of Kernel Traits and Validation of a Major QTL for Kemel Length-Width Ratio Using SNP and Bulked Segregant Analysis in Wheat. Sci. Rep. 2020, 10, 1-12, doi:10.1038/s41598-019-56979-7.

24. Mohan, A.; Grant, N.P.; Schillinger, W.F.; Gill, K.S. Characterizing reduced height wheat mutants for traits affecting abiotic stress and photosynthesis during seedling growth. Physiol. Plant. 2021, 172, 233-246, doi:10.1111/ppl.13321.

25. Mo, Y.; Vanzetti, L.S.; Hale, I.; Spagnolo, E.J.; Guidobaldi, F.; Al-Oboudi, J.; Odle, N.; Pearce, S.; Helguera, M.; Dubcovsky, J. Identification and characterization of Rht25, a locus on chromosome arm 6AS affecting wheat plant height, heading time, and spike development. Theor. Appl. Genet. 2018, 131, 2021-2035, doi:10.1007/s00122-018-3130-6.

26. Guan, P.; Shen, X.; Mu, Q.; Wang, Y.; Wang, X.; Chen, Y.; Zhao, Y.; Chen, X.; Zhao, A.; Mao, W.; et al. Dissection and validation of a QTL cluster linked to Rht-B1 locus controlling grain weight in common wheat (Triticum aestivum L.) using near-isogenic lines. Theor. Appl. Genet. 2020, 133, 2639-2653, doi:10.1007/s00122-020-03622-z.

27. Duan, X.; Yu, H.; Ma, W.; Sun, J.; Zhao, Y.; Yang, R.; Ning, T.; Li, Q.; Liu, Q.; Guo, T.; et al. A major and stable QTL controlling wheat thousand grain weight: identification, characterization, and CAPS marker development. Mol. Breed. 2020, 40, doi:10.1007/s11032-020-01147-3.

28. Chen, W.; Sun, D.; Li, R.; Wang, S.; Shi, Y.; Zhang, W.; Jing, R. Mining the stable quantitative trait loci for agronomic traits in wheat (Triticum aestivum L.) based on an introgression line population. BMC Plant Biol. 2020, 20, 1-9, doi:10.1186/s12870-020-02488-Z.

29. Li, Q.; Pan, Z.; Gao, Y.; Li, T.; Liang, J.; Zhang, Z.; Zhang, H.; Deng, G.; Long, H.; Yu, M. Quantitative Trait Locus (QTLs) Mapping for Quality Traits of Wheat Based on High Density Genetic Map Combined With Bulked Segregant Analysis RNA-seq (BSR-Seq) Indicates That the Basic 7S Globulin Gene Is Related to Falling Number. Front. Plant Sci. 2020, 11, 1-21, doi:10.3389/fpls.2020.600788.

30. Cui, F.; Zhao, C.; Ding, A.; Li, J.; Wang, L.; Li, X.; Bao, Y.; Li, J.; Wang, H. Construction of an integrative linkage map and QTL mapping of grain yield-related traits using three related wheat RIL populations. Theor. Appl. Genet. 2014, 127, 659-675, doi:10.1007/s00122-013-2249-8.

31. Li, F.; Wen, W.; He, Z.; Liu, J.; Jin, H.; Cao, S.; Geng, H.; Yan, J. Genome - wide linkage mapping of yield - related traits in three Chinese bread wheat populations using high - density SNP markers. Theor. Appl. Genet. 2018, 131, 1903-1924, doi:10.1007/s00122-018-3122-6.

32. Lee, H.S.; Jung, J.U.; Kang, C.S.; Heo, H.Y.; Park, C.S. Mapping of QTL for yield and its related traits in a doubled haploid population of Korean wheat. Plant Biotechnol. Rep. 2014, 8, 443-454, doi:10.1007/s11816-014-0337-0.

33. Maphosa, L.; Langridge, P.; Taylor, H.; Parent, B.; Emebiri, L.C.; Kuchel, H.; Reynolds, M.P.; Chalmers, K.J.; Okada, A.; Edwards, J.; et al. Genetic control of grain yield and grain physical characteristics in a bread wheat population grown under a range of environmental conditions. Theor. Appl. Genet. 2014, 127, 1607-1624, doi:10.1007/s00122-014-2322-y.

34. Kumar, A.; Mantovani, E.E.; Seetan, R.; Soltani, A.; Echeverry-Solarte, M.; Jain, S.; Simsek, S.; Doehlert, D.; Alamri, M.S.; Elias, E.M.; et al. Dissection of Genetic Factors underlying Wheat Kemel Shape and Size in an Elite x Nonadapted Cross using a High Density SNP Linkage Map. Plant Genome 2016, 9 , doi:10.3835/plantgenome2015.09.0081.

35. McCartney, C.A.; Somers, D.J.; Humphreys, D.G.; Lukow, O.; Ames, N.; Noll, J.; Cloutier, S.; McCallum, B.D. Mapping quantitative trait loci controlling agronomic traits in the spring wheat cross RL4452 x "AC Domain." Genome 2005, 48, 870-883, doi:10.1139/G05-055.

36. Mohler, V.; Albrecht, T.; Castell, A.; Diethelm, M.; Schweizer, G.; Hartl, L. Considering causal genes in the genetic dissection of kernel traits in common wheat. J. Appl. Genet. 2016, 57, 467-476, doi:10.1007/s13353-016-0349-2.

37. Yan, L.; Liang, F.; Xu, H.; Zhang, X.; Zhai, H.; Sun, Q.; Ni, Z. Identification of QTL for grain size and shape on the D genome of natural and synthetic allohexaploid wheats with near-identical AABB genomes. Front. Plant Sci. 2017, 8, 1-14, doi:10.3389/fpls.2017.01705.

38. Tian, X.; Wen, W.; Xie, L.; Fu, L.; Xu, D.; Fu, C.; Wang, D.; Chen, X.; Xia, X.; Chen, Q.; et al. Molecular mapping of reduced plant height gene Rht24 in bread wheat. Front. Plant Sci. 2017, 8, 1-9, doi:10.3389/fpls.2017.01379.

39. Daba, S.D.; Tyagi, P.; Brown-Guedira, G.; Mohammadi, M. Genome-wide association study in historical and contemporary U.S. winter wheats identifies height-reducing loci. Crop J. 2020, 8, 243-251, doi:10.1016/j.cj.2019.09.005.

40. Luján Basile, S.M.; Ramírez, I.A.; Crescente, J.M.; Conde, M.B.; Demichelis, M.; Abbate, P.; Rogers, W.J.; Pontaroli, A.C.; Helguera, M.; Vanzetti, L.S. Haplotype block analysis of an Argentinean hexaploid wheat collection and GWAS for yield components and adaptation. BMC Plant Biol. 2019, 19, 1-16, doi:10.1186/s12870-019-2015-4.

41. Ford, B.A.; Foo, E.; Sharwood, R.; Karafiatova, M.; Vrána, J.; MacMillan, C.; Nichols, D.S.; Steuernagel, B.; Uauy, C.; Doležel, J.; et al. Rht18 Semidwarfism in Wheat Is Due to Increased GA 2-oxidaseA9 Expression and Reduced GA Content. Plant Physiol. 2018, 177, 168-180, doi:10.1104/pp.18.00023.

42. Liu, K.; Sun, X.; Ning, T.; Duan, X.; Wang, Q.; Liu, T.; An, Y.; Guan, X.; Tian, J.; Chen, J. Genetic dissection of wheat panicle traits using linkage analysis and a genome-wide association study. Theor. Appl. Genet. 2018, 131, 1073-1090, doi:10.1007/s00122-018-3059-9.

43. Cao, P.; Liang, X.; Zhao, H.; Feng, B.; Xu, E.; Wang, L.; Hu, Y. Identification of the quantitative trait loci controlling spike-related traits in hexaploid wheat (Triticum aestivum L.). Planta 2019, 250, 1967-1981, doi:10.1007/s00425-019-03278-0.

Page $13 / 17$ 
44. Ma, J.; Tu, Y.; Zhu, J.; Luo, W.; Liu, H.; Li, C.; Li, S.; Liu, J.; Ding, P.; Habib, A.; et al. Flag leaf size and posture of bread wheat: genetic dissection, QTL validation and their relationships with yield-related traits. Theor. Appl. Genet. 2020, 133, 297-315, doi:10.1007/s00122-019-03458-2.

45. Gao, F.; Wen, W.; Liu, J.; Rasheed, A.; Yin, G.; Xia, X.; Wu, X.; He, Z. Genome-Wide Linkage Mapping of QTL for Yield Components, Plant Height and YieldRelated Physiological Traits in the Chinese Wheat Cross Zhou 8425B/Chinese Spring. Front. Plant Sci. 2015, 6, 1099, doi:10.3389/fpls.2015.01099

46. Zhang, K.; Wang, J.; Qin, H.; Wei, Z.; Hang, L.; Zhang, P.; Reynolds, M.; Wang, D. Assessment of the individual and combined effects of Rht8 and Ppd-D1a on plant height, time to heading and yield traits in common wheat. Crop J. 2019, 7, 845-856, doi:10.1016/j.cj.2019.06.008.

47. Rebetzke, G.J.; Ellis, M.H.; Bonnett, D.G.; Mickelson, B.; Condon, A.G.; Richards, R.A. Height reduction and agronomic performance for selected gibberellinresponsive dwarfing genes in bread wheat (Triticum aestivum L.). F. Crop. Res. 2012, 126, 87-96, doi:10.1016/j.fcr.2011.09.022.

48. Wang, Y.; Du, Y.; Yang, Z.; Chen, L.; Condon, A.G.; Hu, Y.G. Comparing the effects of GA-responsive dwarfing genes Rht13 and Rht8 on plant height and some agronomic traits in common wheat. F. Crop. Res. 2015, 179, 35-43, doi:10.1016/j.fcr.2015.04.010.

49. Yang, W.; Liu, D.; Li, J.; Zhang, L.; Wei, H.; Hu, X.; Zheng, Y.; He, Z.; Zou, Y. Synthetic hexaploid wheat and its utilization for wheat genetic improvement in China. J. Genet. Genomics 2009, 36, 539-546, doi:10.1016/S1673-8527(08)60145-9.

50. Sukumaran, S.; Lopes, M.; Dreisigacker, S.; Reynolds, M. Genetic analysis of multi-environmental spring wheat trials identifies genomic regions for locusspecific trade-offs for grain weight and grain number. Theor. Appl. Genet. 2018, 131, 985-998, doi:10.1007/s00122-017-3037-7.

51. Su, Z.; Hao, C.; Wang, L.; Dong, Y.; Zhang, X. Identification and development of a functional marker of TaGW2 associated with grain weight in bread wheat (Triticum aestivum L.). Theor. Appl. Genet. 2011, 122, 211-223, doi:10.1007/s00122-010-1437-z.

52. Luo, W.; Ma, J.; Zhou, X.H.; Sun, M.; Kong, X.C.; Wei, Y.M.; Jiang, Y.F.; Qi, P.F.; Jiang, Q.T.; Liu, Y.X.; et al. Identification of quantitative trait loci controlling agronomic traits indicates breeding potential of tibetan semiwild wheat (Triticum aestivum ssp. tibetanum). Crop Sci. 2016, 56, 2410-2420, doi:10.2135/cropsci2015.11.0700.

53. Würschum, T.; Leiser, W.L.; Langer, S.M.; Tucker, M.R.; Longin, C.F.H. Phenotypic and genetic analysis of spike and kernel characteristics in wheat reveals long-term genetic trends of grain yield components. Theor. Appl. Genet. 2018, 131, 2071-2084, doi:10.1007/s00122-018-3133-3.

54. Liu, G.; Xu, S.B.; Ni, Z.F.; Xie, C.J.; Qin, D.D.; Li, J.; Lu, L.H.; Zhang, J.P.; Peng, H.R.; Sun, Q.X. Molecular dissection of plant height QTLs using recombinant inbred lines from hybrids between common wheat (Triticum aestivum L.) and spelt wheat (Triticum spelta L.). Chinese Sci. Bull. 2011, 56, 1897-1903, doi:10.1007/s11434-011-4506-z.

55. Chai, L.; Chen, Z.; Bian, R.; Zhai, H.; Cheng, X.; Peng, H.; Yao, Y.; Hu, Z.; Xin, M.; Guo, W.; et al. Dissection of two quantitative trait loci with pleiotropic effects on plant height and spike length linked in coupling phase on the short arm of chromosome 2D of common wheat (Triticum aestivum L.). Theor. Appl. Genet. 2019, 132, 1815-1831, doi:10.1007/s00122-019-03318-z.

56. Borrill, P.; Ramirez-Gonzalez, R.; Uauy, C. expVIP: A customizable RNA-seq data analysis and visualization platform. Plant Physiol. 2016, 170, 2172-2186, doi:10.1104/pp.15.01667.

57. Ramírez-González, R.H.; Borrill, P.; Lang, D.; Harrington, S.A.; Brinton, J.; Venturini, L.; Davey, M.; Jacobs, J.; Van Ex, F.; Pasha, A.; et al. The transcriptional landscape of polyploid wheat. Science (80-.). 2018, 361, doi:10.1126/science.aar6089.

58. Miao, J.; Yang, Z.; Zhang, D.; Wang, Y.; Xu, M.; Zhou, L.; Wang, J.; Wu, S.; Yao, Y.; Du, X.; et al. Mutation of RGG2, which encodes a type B heterotrimeric G protein y subunit, increases grain size and yield production in rice. Plant Biotechnol. J. 2019, 17, 650-664, doi:10.1111/pbi.13005.

59. Li, N.; Li, Y. Ubiquitin-mediated control of seed size in plants. Front. Plant Sci. 2014, 5, 1-6, doi:10.3389/fpls.2014.00332.

60. Smalle, J.; Kurepa, J.; Yang, P.; Emborg, T.J.; Babiychuk, E.; Kushnir, S.; Vierstra, R.D. The pleiotropic role of the 26S proteasome subunit RPN10 in Arabidopsis growth and development supports a substrate-specific function in abscisic acid signaling. Plant Cell 2003, 15, 965-980, doi: $10.1105 /$ tpc.009217.

61. Li, N.; Xu, R.; Li, Y. Molecular Networks of Seed Size Control in Plants. Annu. Rev. Plant Biol. 2019, 70, 435-463, doi:10.1146/annurev-arplant-050718095851.

62. Li, Q.; Li, L.; Yang, X.; Warburton, M.L.; Bai, G.; Dai, J.; Li, J.; Yan, J. Relationship, evolutionary fate and function of two maize co-orthologs of rice GW2 associated with kernel size and weight. BMC Plant Biol. 2010, 10, 1-15, doi:10.1186/1471-2229-10-143.

63. Chen, C.; Chen, H.; Zhang, Y.; Thomas, H.R.; Frank, M.H.; He, Y.; Xia, R. TBtools: An Integrative Toolkit Developed for Interactive Analyses of Big Biological Data. Mol. Plant 2020, 13, 1194-1202, doi:10.1016/j.molp.2020.06.009.

64. Smith, S.E.; Kuehl, R.O.; Ray, I.M.; Hui, R.; Soleri, D. Evaluation of simple methods for estimating broad-sense heritability in stands of randomly planted genotypes. Crop Sci. 1998, 38, 1125-1129, doi:10.2135/cropsci1998.0011183X003800050003x.

65. Alaux, M.; Rogers, J.; Letellier, T.; Flores, R.; Alfama, F.; Pommier, C.; Mohellibi, N.; Durand, S.; Kimmel, E.; Michotey, C.; et al. Linking the International Wheat Genome Sequencing Consortium bread wheat reference genome sequence to wheat genetic and phenomic data. Genome Biol. $2018,19: 111$. https://doi.org/10.1186/s13059-018-1491-4

66. Appels, R.; Eversole, K.; Feuillet, C.; Keller, B.; Rogers, J.; Stein, N.; Pozniak, C.J.; Choulet, F.; Distelfeld, A.; Poland, J.; et al. Shifting the limits in wheat research and breeding using a fully annotated reference genome. Science (80-). 2018, 361, doi:10.1126/science.aar7191.

67. Chen, Y.; Song, W.; Xie, X.; Wang, Z.; Guan, P.; Peng, H.; Jiao, Y.; Ni, Z.; Sun, Q.; Guo, W. A Collinearity-Incorporating Homology Inference Strategy for Connecting Emerging Assemblies in the Triticeae Tribe as a Pilot Practice in the Plant Pangenomic Era. Mol. Plant 2020, 13, 1694-1708, doi:10.1016/j.molp.2020.09.019.

68. Supplementary file

\section{Figures}




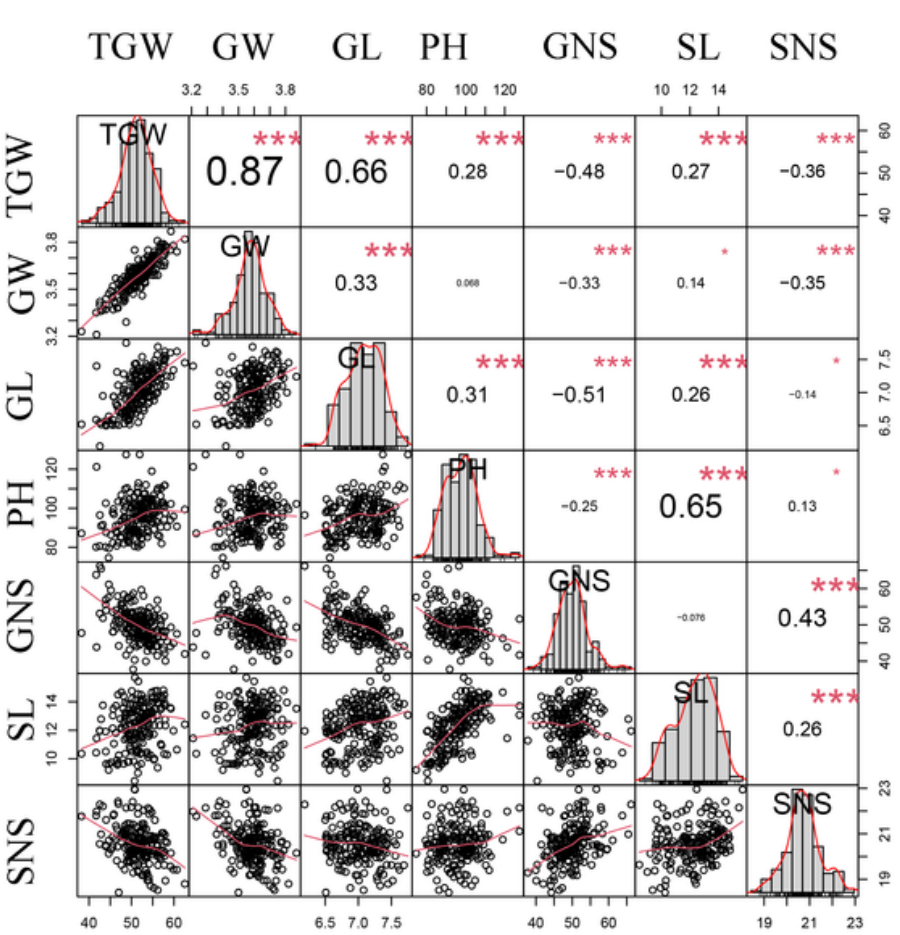

\section{B}



Figure 1

Phenotypic performances, distribution, and correlation coefficients of thousand grain weight (TGW), grain number per spike (GNS), grain width (GW), grain length (GL), plant height (PH), spike length (SL) and spikelet number per spike (SNS) in the CM42×CM39 RIL lines based on the BLUP datasets (A). B Visualization of correlations among investigated traits; Darkred and darkgreen lines represent positive and negative correlation, respectively; The line weight represent the size of correlation coefficient; * ** and *** represent significant at $P<0.05, P<0.01$ and $P<0.001$, respectively. 

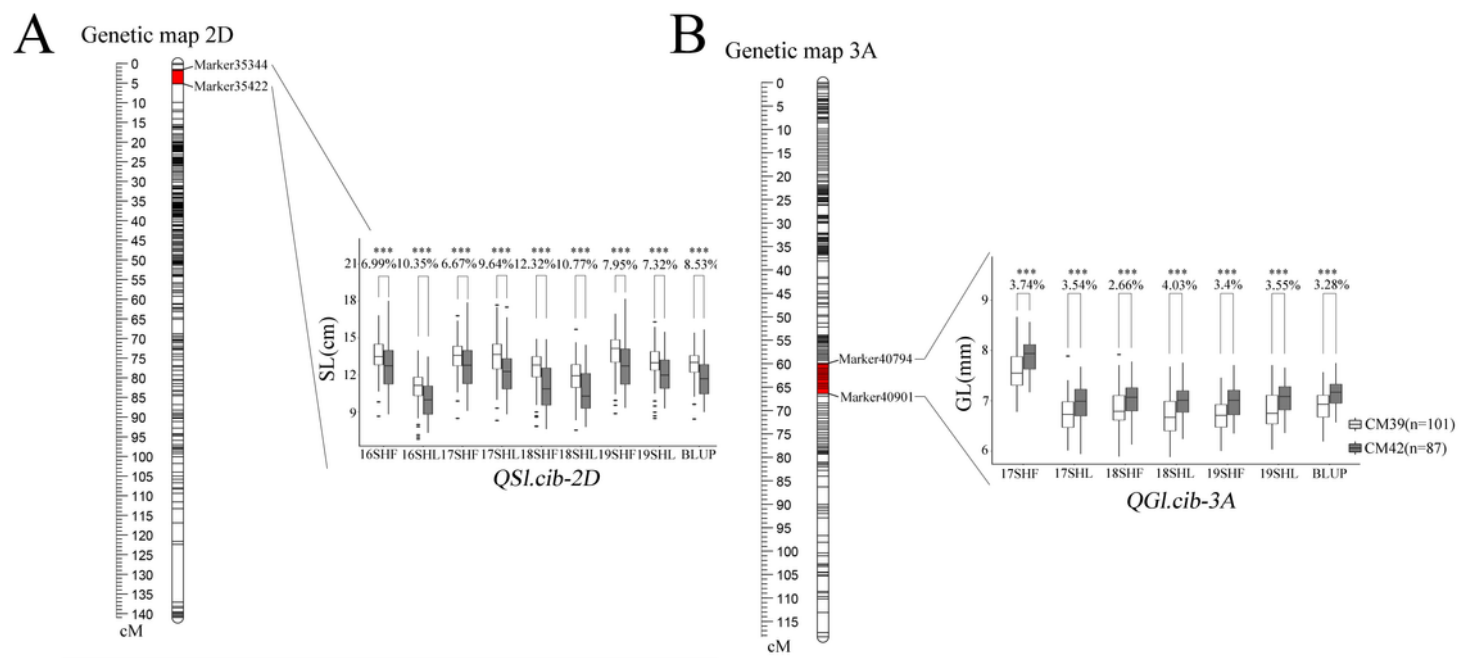

C Genetic map 6A

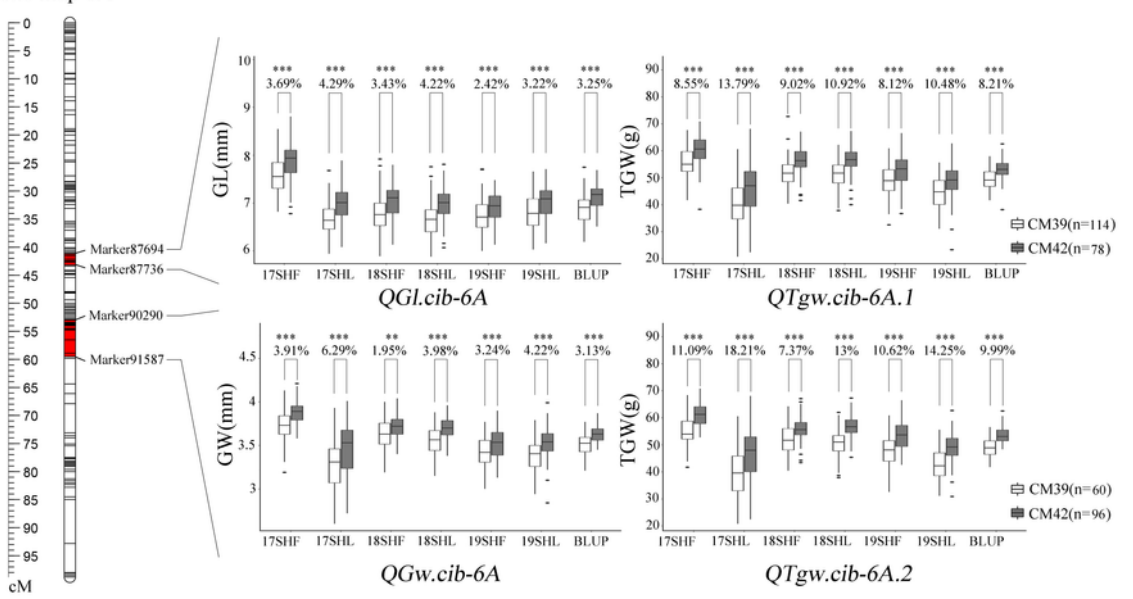

\section{Figure 2}

Genetic map of six major QTLs, and their effects on corresponding traits in the CM42×CM39 RIL population. Six mjor QTLs including QSI.cib-2D (A), QGI.cib3A (B), QGI.cib-6A (C), QTgw.cib-6A.1 (C), QGw.cib-6A (C) and QTgw.cib-6A.2 (C). The lines drawn on the bar (chromosome) indicate the mapped markers; cM, centimorgans; CM42 and CM39 indicate the lines with the alleles from CM42 and CM39, resepectively; ** and *** represent significance at $\mathrm{P}<0.01$ and $\mathrm{P}<$ 0.001 , respectively. 


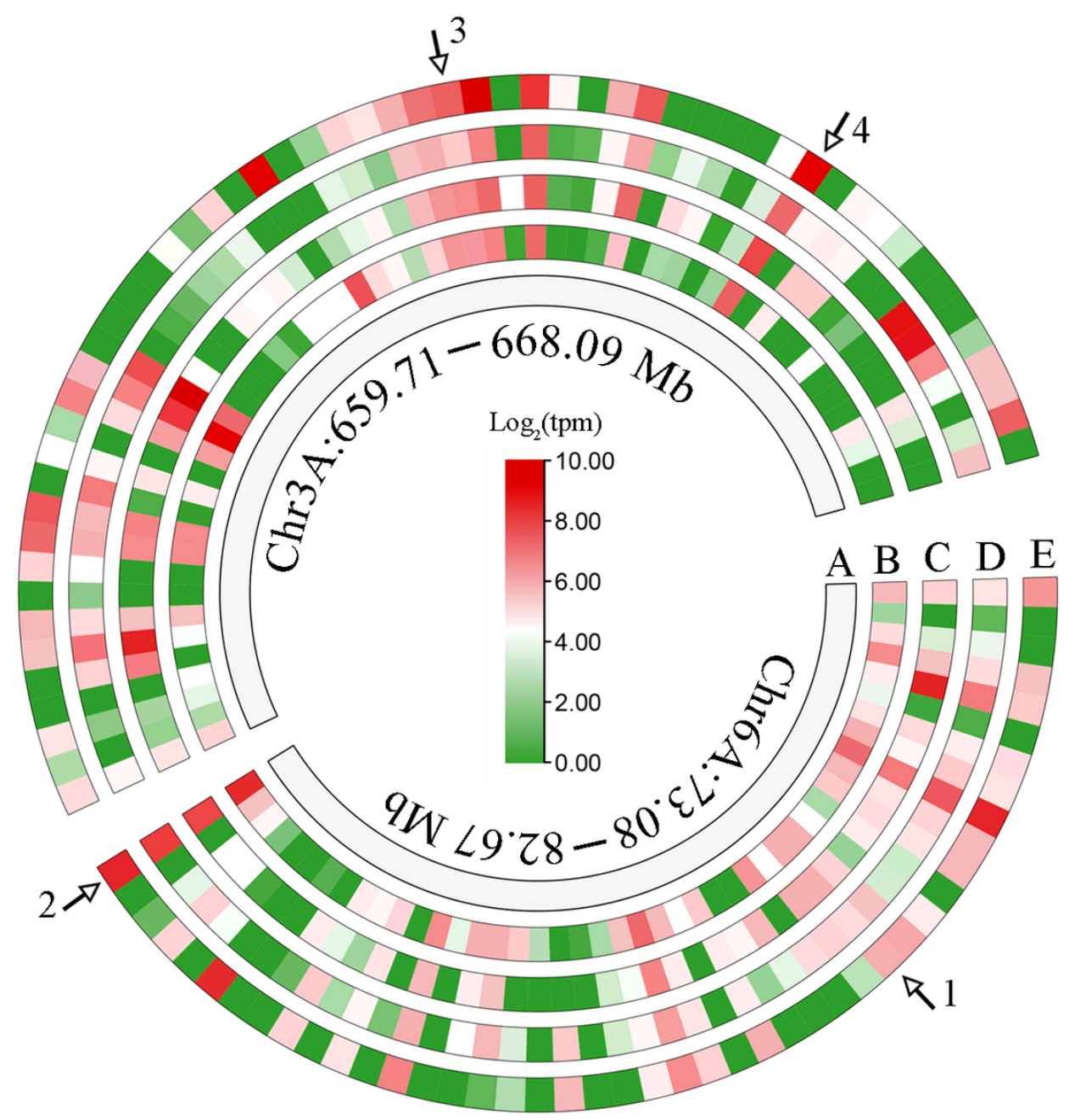

Figure 3

Expression pattern of genes within the QTgw.cib-6A.1/QGI.cib-6A and QGI.cib-3A intervals. 1, 2, 3 and 4 marked by the arrow represent TraesCS6A02G107800, TraesCS6A02G112400, TraesCS3A02G421900 andTraesCS3A02G424000, respectively; A represents the physical interval of QTgw.cib-6A.1/QGI.cib-6A and QGI.cib-3A on chromosome 6A and 3A; B, C, D and E represent root, leaf/shoot, spike and, grain, respectively.

\section{Supplementary Files}

This is a list of supplementary files associated with this preprint. Click to download.

- Figures1.tif

- SupplementaryTables.xls 